\title{
EDITORIAL
}

Nuri Aksel • Hans Irschik • Michael Krommer •

Alfredo Soldati • George Weng

\section{Special Issue dedicated to the memory of Franz Ziegler}

Received: 10 November 2017 / Published online: 17 January 2018

(C) Springer-Verlag GmbH Austria, part of Springer Nature 2018

On January 4, 2016, Franz Ziegler, long-term Editor of Acta Mechanica, passed away unexpectedly. A comprehensive obituary, acknowledging life and work of this truly outstanding scholar of mechanics, was published in Acta Mechanica, Volume 227, 939-941 (2016). In addition, the undersigned, who were serving in the Board of Editors of Acta Mechanica in 2016, have decided to edit a special issue dedicated to the memory of Franz Ziegler. We are happy to present this volume in the following. It contains 36 contributions from all over the world, referring to a broad field of theoretical and applied mechanics of solids and fluids, and it highlights the strong belief of Franz Ziegler in mechanics as a firm foundation of engineering and natural sciences as a whole.

N. Aksel

Faculty of Engineering Science, Department of Applied Mechanics and Fluid Dynamics, University of Bayreuth, 95440 Bayreuth, Germany

H. Irschik $(\bowtie)$

Johannes Kepler Universität, Linz, Austria

E-mail: hans.irschik@jku.at

M. Krommer Institute of Mechanics and Mechatronics, Division for Mechanics of Solids, Vienna University of Technology, Getreidemarkt 9/E325/A1, 1060 Vienna, Austria

A. Soldati

Institute of Fluid Mechanics and Heat Transfer, Vienna University of Technology, Getreidemarkt 9, 1060 Vienna, Austria

G. Weng

Department of Mechanical \& Aerospace Engineering Rutgers, The State University of New Jersey, 98 Brett Road,

Piscataway, NJ 08854, USA 